\title{
Development and validation of a frailty index in the Longitudinal Aging Study Amsterdam
}

\author{
Emiel O. Hoogendijk ${ }^{1}\left(\mathbb{D} \cdot\right.$ Olga Theou $^{2} \cdot$ Kenneth Rockwood $^{2} \cdot$ Bregje D. Onwuteaka- $^{3}$ \\ Philipsen $^{3}$ - Dorly J. H. Deeg ${ }^{1}$ Martijn Huisman ${ }^{1,4}$
}

Received: 15 September 2016/ Accepted: 17 November 2016/Published online: 28 November 2016

(c) The Author(s) 2016. This article is published with open access at Springerlink.com

\begin{abstract}
Background Frailty is a state of increased vulnerability to adverse outcomes. The frailty index (FI), defined by the deficit accumulation approach, is a sensitive instrument to measure levels of frailty, and therefore important for longitudinal studies of aging.

Aims To develop an FI in the Longitudinal Aging Study Amsterdam (LASA), and to examine the predictive validity of this FI for 19-year mortality.

Methods LASA is an ongoing study among Dutch older adults, based on a nationally representative sample. A 32-item FI (LASA-FI) was developed at the second LASA measurement wave (1995-1996) among 2218 people aged 57-88 years. An FI score between 0 and 1 was calculated for each individual. The LASA-FI included health deficits from the physical, mental and cognitive domain and can be constructed for most LASA measurement waves. Associations with 19-year mortality were assessed using KaplanMeier curves and Cox proportional hazards models.

Results The mean LASA-FI score was 0.19 (SD $=0.12$ ), with a $99 \%$ upper limit of 0.53 . Scores were higher in
\end{abstract}

Emiel O. Hoogendijk

e.hoogendijk@vumc.nl

1 Department of Epidemiology and Biostatistics, EMGO+ Institute for Health and Care Research, VU University Medical Center, Amsterdam, The Netherlands

2 Division of Geriatric Medicine, Department of Medicine, Dalhousie University, Halifax, NS, Canada

3 Department of Public and Occupational Health, EMGO+ Institute for Health and Care Research, VU University Medical Center, Amsterdam, The Netherlands

4 Department of Sociology, VU University, Amsterdam, The Netherlands women than men $\quad$ (women $=0.20, \quad \mathrm{SD}=0.13 \quad$ vs. men $=0.17, \mathrm{SD}=0.11, p<0.001)$. The average age-related increase in the log-transformed LASA-FI score was $3.5 \%$ per year. In a model adjusted for age and sex, the FI score was significantly associated with 19-year all-cause mortality (HR per $0.01=1.03$, 95\% CI 1.03-1.04, $p<0.001)$.

Discussion/conclusions The key characteristics of the LASA-FI were in line with findings from previous FI studies in population-based samples of older people. The LASA-FI score was associated with mortality and may serve as an internal and external reference value.

Keywords Frail elderly · Deficit accumulation · Frailty index $\cdot$ Longitudinal study $\cdot$ Mortality

\section{Introduction}

Frailty is a state of increased vulnerability to adverse outcomes, such as falls, functional decline, hospitalization and death [1]. As the clinical importance of the concept of frailty is increasingly recognized, it is of major importance to identify frail older adults [2]. Many operational definitions of frailty exist [3]. One of the most widely used is the deficit accumulation approach, also known as the frailty index (FI). It involves the accumulation of diseases, symptoms, signs, disabilities or any deficiency in health with age, based on the idea that a greater number of health deficits indicate higher frailty [4]. Although health deficits increase with age, the FI characterizes age-related decline in health more efficiently than does chronological age [5]. Moreover, the FI has been shown to be a better predictor of adverse outcomes than chronological age [6] and even some other indices of biological age [7]. 
The items included in the FI are not fixed. As long as certain requirements are met, such as the type and number of health deficits included (it is recommended to include at least 30 health deficits representing several organ systems), it does not matter what combinations of health deficits are used [8]. This flexibility allows an FI to be constructed retrospectively in almost any dataset that includes comprehensive information on health and functioning.

The application of an FI may have added value for longitudinal studies in older populations. For these studies, a valid and sensitive frailty instrument is important so that the impact of frailty on various outcomes can be studied, as can its trajectory. In addition, it is imperative to apply the FI in different studies, to be able to compare its characteristics across different countries and settings. Until now, very few studies on the FI made use of data over an extended time period, and most studies were performed in North America [9-11].

The Longitudinal Aging Study Amsterdam (LASA) $[12,13]$, an ongoing study among Dutch older adults, is among the few European studies with a very long followup time. So far, the FI has not yet been constructed with LASA data. Therefore, the aim of this study was to develop and validate an FI in LASA. We described its characteristics and studied its relationship with chronological age. Since the validity of any frailty instrument largely depends on its ability to predict adverse outcomes, and in particular death, we validated this FI for 19-year all-cause mortality.

\section{Methods}

\section{Design and study sample}

LASA is an ongoing study on physical, emotional, cognitive and social functioning of older adults in the Netherlands. Details on the sampling and data collection of LASA have been published elsewhere [12, 13]. In summary, a nationally representative survey was conducted in 1992-1993 among 3107 respondents between the ages of 55 and 85. Follow-up measurements are collected approximately every 3 years. Data are collected in a faceto-face main interview in the respondent's home by trained interviewers. During the main interview, respondents are asked to participate in a subsequent medical interview. After consent, a separate visit is scheduled in which clinical measurements are administered and additional questions are asked. The study received approval by the medical ethics committee of the VU University medical center. Signed informed consent was obtained from all study participants.

For the current study, data were used from the main interview of the second LASA measurement wave
(1995-1996). Since various instruments were changed or included after the first LASA measurement wave, the second wave was more suitable to use than the first wave. Of the 2302 participants in the main interview, $84(3.6 \%)$ were excluded because frailty level could not be identified due to missing data. This resulted in a final sample of 2218 persons aged 57-88 years.

\section{Frailty index construction}

For the construction of the FI (LASA-FI) we followed the standard procedure described by Searle et al. [8]. Health deficits were included in the LASA-FI, if they (a) were biologically meaningful in representing several organ systems, and (b) were accumulating with age, and not becoming too prevalent at some younger age, and (c) did not contain too many missing values at item level $(<5 \%)$, and (d) were available in the main interview of LASA at different measurement waves (to have the opportunity to study changes in LASA-FI score in future research).

We screened all questionnaires from the LASA main interview. From 34 potential variables we excluded two variables (hearing and vision), because they were not included in the LASA main interview at all subsequent measurement waves. Thus, 32 health deficits from the physical, mental and cognitive domain were used to construct the LASA-FI. Variables included self-reported chronic conditions: cardiac disease, peripheral arterial disease, stroke, diabetes, lung disease, cancer, arthritis, hypertension, a maximum of two other diseases and incontinence [14]; functional limitations: the ability to walk 15 stairs without resting, to (un)dress self, to sit and stand up from a chair, to cut own toenails, to walk outside for 5 min without stopping and to use public transportation [15]; self-rated health: the questions "How is your health in general?" and "How is your health compared to other people of your age?" [16]; six items from the CES-D depression scale: the extent to which people feel depressed, feel everything is an effort, feel happy, feel lonely, enjoy life and could not get going [17]; physical activity: based on the LASA physical activity questionnaire (LAPAQ) [18]; self-reported memory complaints [19]; four items from the Mini-Mental State Examination (MMSE): orientation in time, orientation in place, attention and recall [20]; and physical performance measured by gait speed [21]. See Table 1 for an overview of all included variables and cutoff values. All deficits were scored between 0 and 1 , where 0 indicates the absence of the deficit and 1 the presence of a deficit.

We did not calculate a frailty score for participants with more than $20 \%$ missing variables of the LASA-FI. This commonly used criterion allows for maximum use of available data without excessive reliance on imputation 
Table 1 Overview of the variables included in the frailty index

\begin{tabular}{|c|c|c|}
\hline No. & Deficit & Cutoff values \\
\hline 1 & Cardiac disease & No $=0$, yes $=1$ \\
\hline 2 & Peripheral arterial disease & No $=0$, yes $=1$ \\
\hline 3 & Stroke & No $=0$, yes $=1$ \\
\hline 4 & Diabetes & No $=0$, yes $=1$ \\
\hline 5 & Lung disease & No $=0$, yes $=1$ \\
\hline 6 & Cancer & No $=0$, yes $=1$ \\
\hline 7 & Arthritis & No $=0$, yes $=1$ \\
\hline 8 & Hypertension & No $=0$, yes $=1$ \\
\hline 9 & Other chronic disease 1 & No $=0$, yes $=1$ \\
\hline 10 & Other chronic disease 2 & No $=0$, yes $=1$ \\
\hline 11 & Incontinence & No $=0$, yes $=1$ \\
\hline 12 & $\begin{array}{l}\text { Walk up/down staircase } 15 \text { steps without } \\
\text { resting }\end{array}$ & $\begin{array}{l}\text { Yes }=0 \text {, yes, with some difficulty }=0.25 \text {, yes, with much difficulty }=0.50 \text {, only with } \\
\text { help }=0.75, \text { No }=1\end{array}$ \\
\hline 13 & Dress/undress self & $\begin{array}{l}\text { Yes }=0 \text {, yes, with some difficulty }=0.25 \text {, yes, with much difficulty }=0.50 \text {, only with } \\
\text { help }=0.75, \text { no }=1\end{array}$ \\
\hline 14 & Sit down/stand up from chair & $\begin{array}{l}\text { Yes }=0 \text {, yes, with some difficulty }=0.25 \text {, yes, with much difficulty }=0.50 \text {, only with } \\
\text { help }=0.75, \text { no }=1\end{array}$ \\
\hline 15 & Cut own toenails & $\begin{array}{l}\text { Yes }=0 \text {, yes, with some difficulty }=0.25 \text {, yes, with much difficulty }=0.50 \text {, only with } \\
\text { help }=0.75 \text {, no }=1\end{array}$ \\
\hline 16 & Walk outside 5 min without stopping & $\begin{array}{l}\text { Yes }=0 \text {, yes, with some difficulty }=0.25 \text {, yes, with much difficulty }=0.50 \text {, only with } \\
\text { help }=0.75 \text {, no }=1\end{array}$ \\
\hline 17 & Use of transportation & $\begin{array}{l}\text { Yes }=0 \text {, yes, with some difficulty }=0.25 \text {, yes, with much difficulty }=0.50 \text {, only with } \\
\text { help }=0.75, \text { no }=1\end{array}$ \\
\hline 18 & How is your health in general? & Excellent $=0$, good $=0.25$, fair $=0.50$, sometimes good $/ \mathrm{bad}=0.75$, Poor $=1$ \\
\hline 19 & $\begin{array}{l}\text { How is your health compared to other people } \\
\text { of your age? }\end{array}$ & $\begin{array}{l}\text { Much better/a little better }=0 \text {, just as good }=0.33 \text {, a little worse }=0.66 \text {, much } \\
\text { worse }=1\end{array}$ \\
\hline 20 & Feel depressed (CES-D) & $\begin{array}{l}\text { Rarely or never }=0, \text { some of the time }=0.33 \text {, occasionally }=0.66, \text { mostly or } \\
\text { always }=1\end{array}$ \\
\hline 21 & Feel everything is an effort (CES-D) & $\begin{array}{l}\text { Rarely or never }=0 \text {, some of the time }=0.33 \text {, occasionally }=0.66 \text {, mostly or } \\
\text { always }=1\end{array}$ \\
\hline 22 & Feel happy (CES-D) & $\begin{array}{l}\text { Mostly or always }=0 \text {, occasionally }=0.33 \text {, some of the time }=0.66 \text {, rarely or } \\
\text { never }=1\end{array}$ \\
\hline 23 & Feel lonely (CES-D) & $\begin{array}{l}\text { Rarely or never }=0, \text { some of the time }=0.33 \text {, occasionally }=0.66 \text {, mostly or } \\
\text { always }=1\end{array}$ \\
\hline 24 & Enjoy life (CES-D) & $\begin{array}{l}\text { Mostly or always }=0 \text {, occasionally }=0.33 \text {, some of the time }=0.66 \text {, rarely or } \\
\text { never }=1\end{array}$ \\
\hline 25 & Could not get going (CES-D) & $\begin{array}{l}\text { Rarely or never }=0, \text { some of the time }=0.33 \text {, occasionally }=0.66 \text {, mostly or } \\
\text { always }=1\end{array}$ \\
\hline 26 & Physical activity (LAPAQ) & $\begin{array}{l}\text { High (five or more activities })=0 \text {, medium }(3-4 \text { activities })=0.33 \text {, low }(1-2 \\
\text { activities })=0.66 \text {, no activities }=1\end{array}$ \\
\hline 27 & Memory complaints & No $=0$, yes $=1$ \\
\hline 28 & Orientation time (MMSE) & Five correct $=0$, one wrong $=0.50$, two or more wrong $=1$ \\
\hline 29 & Orientation place (MMSE) & Five correct $=0$, one wrong $=0.50$, two or more wrong $=1$ \\
\hline 30 & Attention (MMSE) & Five correct $=0$, one or two wrong $=0.50$, three or more wrong $=1$ \\
\hline 31 & Recall (MMSE) & Three correct $=0$, two correct $=0.50$, one or zero correct $=1$ \\
\hline 32 & Gait speed $(6 \mathrm{~m})$ & Normal $=0$, slow $(>10 \mathrm{~s})$ or physical unable $=1$ \\
\hline
\end{tabular}

procedures [22]. A frailty score was calculated for each participant by dividing the sum of the health deficit scores by the total number of health deficits measured. This resulted in a score between 0 (no deficits present) and 1 (all deficits present). For example, if a person has six points out of 32 , the LASA-FI score was $6 / 32=0.19$. The LASA-FI may be used as a continuous score, or as a dichotomous variable by applying a generally used cutoff point of $\geq 0.25$ 
to indicate frailty [23]. The SPSS syntax for the construction of the LASA-FI will be provided at the LASA study website (www.lasa-vu.nl).

\section{Mortality}

Mortality status was retrieved from registers of the municipalities where respondents were living. All deaths that occurred between the baseline measurement and July 1,2015 , were recorded $(99.7 \%$ ascertainment for the current sample).

\section{Statistical analysis}

The distribution of the LASA-FI was assessed using a histogram. Descriptive statistics, including the mean FI score and standard deviations, were calculated for the total study population and by sex. Differences between men and women were determined using $t$ test statistics. LASA-FI scores in relation to age were studied in several ways. First, mean FI scores and frailty prevalence were reported by 5-year age groups. Second, mean FI scores were plotted versus age, stratified by sex. Finally, a linear regression analysis with age as independent variable and the natural $\log$ of the LASA-FI as dependent variable was performed to estimate the increase in the LASA-FI score with age.

Kaplan-Meier curves were constructed to estimate 19-year survival for categories of the LASA-FI score. Bivariate and multivariable Cox proportional hazard models were fitted to study the association between the LASA-FI score and 19-year all-cause mortality. Hazard ratios (HR) and $95 \%$ confidence intervals $(95 \% \mathrm{CI})$ were reported for the total population, by sex and by age group $(<80$ years vs. $\geq 80$ years). Multivariable models were adjusted for age and sex (if applicable). Survivors were censored at the end of the follow-up (July 1, 2015). All analyses were performed in SPSS 22 (IBM Corp, Armonk, NY, USA).

\section{Results}

We were able to calculate the LASA-FI for 2218 people out of 2302 available respondents $(96.4 \%)$. Of the 2218 people in the analytic sample, 2092 (94.3\%) had no missing values on the 32 items of the LASA-FI, 103 had only 1 missing item (4.6\%), and 23 had 2 to 6 missing items $(0.1 \%)$. Figure 1 shows the distribution of the LASA-FI, which was skewed to the right.

Table 2 shows the LASA-FI scores for the total study population and stratified by age group and sex. The mean FI score was $0.19(\mathrm{SD}=0.12)$, with a median of 0.16 and a range from 0.00 to 0.71 . The $99 \%$ upper limit was 0.53 .

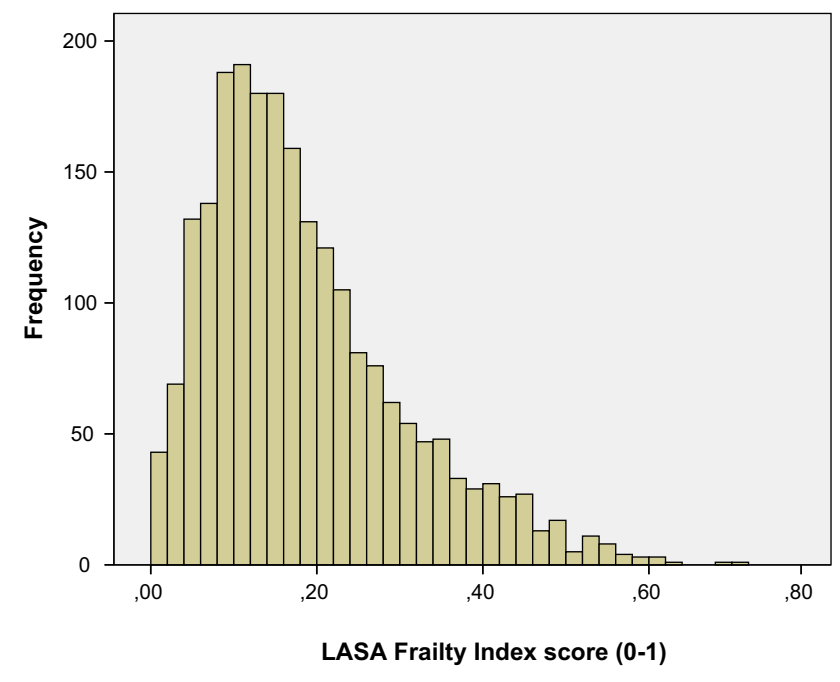

Fig. 1 Distribution of the frailty index at baseline $(N=2218)$

Mean FI scores were higher in women than in men (women $=0.20, \mathrm{SD}=0.13$ vs. men $=0.17, \mathrm{SD}=0.11$, $p<0.001$ ). Table 2 also shows the frailty prevalence when applying the cutoff of 0.25 and higher. Overall, $23.9 \%$ of the respondents was considered to be frail. Frailty prevalence was higher in women $(28.8 \%)$ than in men $(18.4 \%)$.

Mean FI scores and frailty prevalence increased with age in both men and women (Fig. 2). Using the natural log of the FI in linear regression, the overall slope of the deficit accumulation in relation to age was 0.035 ( $\mathrm{SE}=0.002$, $p<0.001$ ), which means that the log-transformed FI score increased on average $3.5 \%$ per year.

Of the study sample of 2218 respondents, 1520 (68.5\%) died during the 19-year follow-up. The median survival time was 13.1 years. People with higher LASA-FI scores had a lower probability of survival (Fig. 3). Table 3 shows the HRs for 19-year all-cause mortality (bivariate and multivariable analyses for the total sample and stratified by age group). In the bivariate Cox regression analyses, age, sex and the LASA-FI were each significantly associated with mortality. Each 0.01 increment in FI score remained associated with mortality after adjustment for age and sex $(\mathrm{HR}=1.03 .95 \%$ CI 1.03-1.04). The association between the FI score and mortality seemed to be slightly stronger among men (HR $=1.04,95 \%$ CI $1.03-1.05)$ than among women $(\mathrm{HR}=1.02,95 \% \mathrm{CI} 1.02-1.03)$. The analyses stratified by age group ( $<80$ years and $\geq 80$ years) showed similar results.

\section{Discussion}

In this study, we successfully constructed an FI in LASA. We described its characteristics and validated the LASAFI for 19-year all-cause mortality. The key characteristics 
Table 2 Frailty index score and frailty prevalence by age group

\begin{tabular}{|c|c|c|c|c|c|c|}
\hline \multirow[t]{2}{*}{ Age group } & \multicolumn{3}{|c|}{ Frailty index score } & \multicolumn{3}{|c|}{ Frailty prevalence (score $\geq 0.25$ ) } \\
\hline & $\begin{array}{l}\text { Overall } \\
\text { Mean (SD) }\end{array}$ & $\begin{array}{l}\text { Women } \\
\text { Mean (SD) }\end{array}$ & $\begin{array}{l}\text { Men } \\
\text { Mean (SD) }\end{array}$ & $\begin{array}{l}\text { Overall } \\
\%\end{array}$ & $\begin{array}{l}\text { Women } \\
\%\end{array}$ & $\begin{array}{l}\text { Men } \\
\%\end{array}$ \\
\hline $57-61(N=300)$ & $0.13(0.08)$ & $0.13(0.08)$ & $0.12(0.08)$ & 8.3 & 7.7 & 9.0 \\
\hline $62-66(N=432)$ & $0.14(0.09)$ & $0.16(0.10)$ & $0.13(0.07)$ & 11.1 & 14.1 & 7.6 \\
\hline $67-71(N=400)$ & $0.15(0.10)$ & $0.17(0.11)$ & $0.13(0.08)$ & 13.5 & 18.1 & 8.2 \\
\hline $72-76(N=342)$ & $0.19(0.11)$ & $0.20(0.120$ & $0.17(0.10)$ & 22.2 & 26.2 & 17.6 \\
\hline $77-81(N=354)$ & $0.23(0.13)$ & $0.26(0.13)$ & $0.21(0.11)$ & 37.0 & 44.6 & 28.8 \\
\hline$\geq 82(N=390)$ & $0.27(0.12)$ & $0.30(0.12)$ & $0.24(0.12)$ & 50.0 & 61.5 & 37.9 \\
\hline Total $(N=2218)$ & $0.19(0.12)$ & $0.20(0.13)$ & $0.17(0.11)$ & 23.9 & 28.8 & 18.4 \\
\hline
\end{tabular}

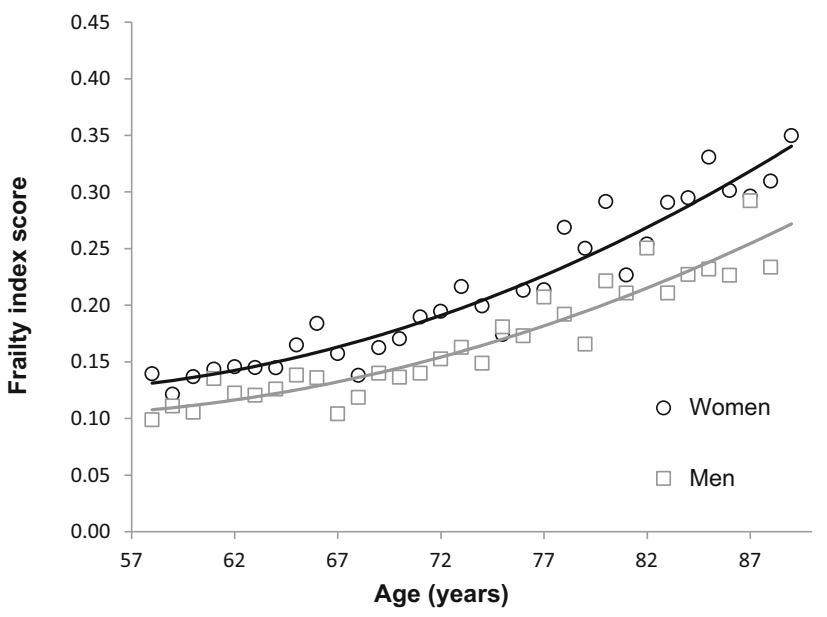

Fig. 2 Average frailty index score by sex and age

of the LASA-FI are consistent with findings from previous studies in population-based samples of older adults: The distribution of the LASA-FI is skewed to the right, the LASA-FI score increases with chronological age, and the average LASA-FI scores are higher in women than in men $[6,8]$. Also, the $99 \%$ upper limit was below 0.7 , as in previous studies $[8,24]$. In the current study, the average rate of deficit accumulation with age was 0.035 , which was comparable to other longitudinal studies in communitybased samples (mean rate of 0.029) [25].

This was one of the first European studies in which the FI was validated for mortality over an extended time period. Our results showed that the LASA-FI was associated with 19-year all-cause mortality. The Kaplan-Meier curves clearly demonstrated that the risk for mortality increased with a higher LASA-FI score. For example, among people with a LASA-FI score $<0.10$ only $19 \%$ died within 10 years, whereas $77 \%$ of the people with a LASA-FI score $\geq 0.40$ died within 10 years.

LASA is based on a nationally representative sample of older adults in the Netherlands. Therefore, the LASA-FI may serve as a reference value for other Dutch studies in more specific populations. In addition, the LASA-FI may

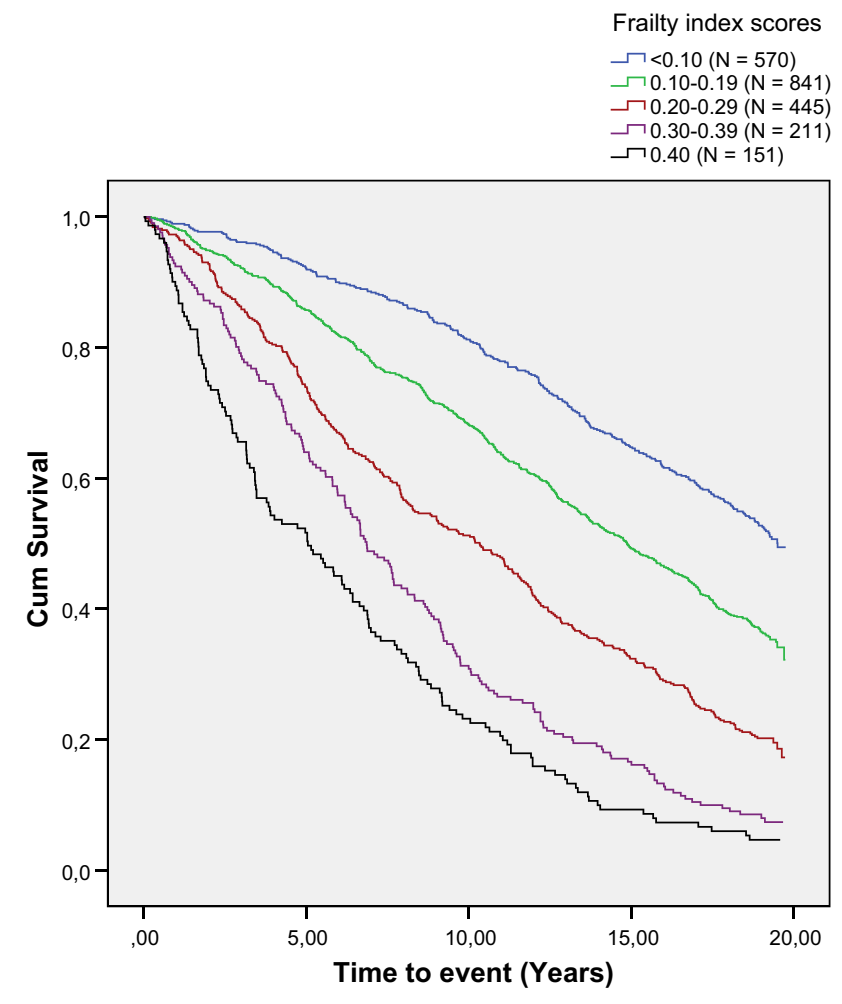

Fig. 3 Kaplan-Meier curves according to frailty index score: proportions of people who survived plotted against time

provide opportunities for comparisons with patient groups in healthcare settings, as the variables included in this FI are often part of routine data collection (e.g., diseases, functional limitations, MMSE). Furthermore, the LASA-FI may be used to select internal reference groups. For example, if researchers would like to select a healthy control group, people with the lowest LASA-FI scores may be selected, as these are the most healthy and stable older adults in the sample.

The LASA-FI also provides many opportunities for future research. First, it may be used as a predictor of adverse outcomes. In this study, we investigated the association with mortality. Further research on the predictive ability of the LASA-FI may be focused on other outcomes 
Table 3 Cox regression analyses for the total sample and stratified by age group: hazard ratios for 19-year all-cause mortality

\begin{tabular}{|c|c|c|c|c|c|c|c|c|}
\hline \multirow[t]{3}{*}{ Variable } & \multirow{2}{*}{\multicolumn{2}{|c|}{$\frac{\text { Unadjusted (bivariate) }}{\text { Overall }}$}} & \multicolumn{6}{|c|}{ Adjusted } \\
\hline & & & \multicolumn{2}{|c|}{ Overall } & \multicolumn{2}{|l|}{ Men } & \multicolumn{2}{|c|}{ Women } \\
\hline & HR & $95 \% \mathrm{CI}$ & HR & $95 \% \mathrm{CI}$ & HR & $95 \% \mathrm{CI}$ & HR & $95 \% \mathrm{CI}$ \\
\hline \multicolumn{9}{|c|}{ Total sample $(N=2218)$} \\
\hline Age & 1.12 & $1.11-1.13$ & 1.11 & $1.10-1.12$ & 1.10 & $1.09-1.11$ & 1.12 & $1.11-1.13$ \\
\hline Sex (male) & 1.43 & $1.30-1.59$ & 1.89 & $1.70-2.01$ & - & - & - & - \\
\hline Frailty index ${ }^{a}$ & 1.04 & $1.04-1.05$ & 1.03 & $1.03-1.04$ & 1.04 & $1.03-1.05$ & 1.02 & $1.02-1.03$ \\
\hline \multicolumn{9}{|c|}{ Age $<80(N=1685)$} \\
\hline Age & 1.13 & $1.12-1.14$ & 1.12 & $1.11-1.14$ & 1.11 & $1.09-1.13$ & 1.14 & $1.12-1.16$ \\
\hline Sex (male) & 1.49 & $1.31-1.69$ & 1.90 & $1.67-2.16$ & - & - & - & - \\
\hline Frailty index ${ }^{a}$ & 1.03 & $1.03-1.04$ & 1.03 & $1.02-1.04$ & 1.04 & $1.03-1.05$ & 1.03 & $1.02-1.03$ \\
\hline \multicolumn{9}{|c|}{ Age $\geq 80(N=533)$} \\
\hline Age & 1.10 & $1.06-1.15$ & 1.09 & $1.05-1.14$ & 1.09 & $1.03-1.15$ & 1.11 & $1.05-1.18$ \\
\hline Sex (male) & 1.39 & $1.17-1.65$ & 1.90 & $1.58-2.30$ & - & - & - & - \\
\hline Frailty index ${ }^{a}$ & 1.03 & $1.02-1.03$ & 1.03 & $1.03-1.04$ & 1.04 & $1.03-1.06$ & 1.02 & $1.01-1.04$ \\
\hline
\end{tabular}

${ }^{a}$ The frailty index hazard ratios measure a 0.01 change on the index such as falls and healthcare use. The LASA-FI may also be studied in relation to the social domain, such as social support and social network characteristics [26]. Second, the LASA-FI may be used to study longitudinal changes in frailty. Previous frailty studies in LASA included another widely used frailty definition: the frailty phenotype [27-29]. This instrument defines frailty based on the number of the following criteria present: weight loss, weak grip strength, exhaustion, slow gait and low physical activity [30]. The frailty phenotype showed good predictive ability for functional decline and mortality [28]. However, as an outcome measure the frailty phenotype is less useful, because with only five items it lacks sensitivity to study changes in frailty states over an extended time period. This is in contrast with the FI, which has the potential to monitor changes in frailty over time in longitudinal studies [31]. Future research may explore the responsiveness of the LASA-FI and compare the predictive ability of the LASAFI with other frailty definitions.

The current FI contains 32 health deficits from the physical, mental and cognitive domain. However, there is some flexibility with regard to the number and type of variables to be included in the LASA-FI. For some research questions, it may be necessary to exclude items. For example, if someone would like to study frailty in relation to cognitive outcomes, the cognitive items of the LASA-FI may be replaced by variables from other domains. Variables from the LASA medical interview may be considered for that purpose, such as peak flow, pain, body mass index and grip strength. However, it should be noted that this may reduce the sample size, as about $85 \%$ of the participants in the main interview agree to participate in this additional interview.

Since FIs can be derived from routinely available healthcare data (e.g., electronic medical records), the FI has great potential for use in clinical practice. Various studies have shown that the FI can be used to identify frail older patients who may benefit from healthcare interventions [32-34]. For example, this has recently been demonstrated in a study using routine data of over 900,000 primary care patient in the UK [32].

In conclusion, the key characteristics of the LASA-FI were in line with previously published FIs. The LASA-FI was significantly associated with mortality and may serve as an internal and external reference value. The instrument provides ample opportunities for future research, where the LASA-FI may be used as a predictor or outcome measure.

Acknowledgements E.H. was supported by a fellowship from the Van Coeverden Adriani foundation. The Longitudinal Aging Study Amsterdam is largely supported by a grant from the Netherlands Ministry of Health Welfare and Sports, Directorate of Long-Term Care.

\section{Compliance with ethical standards}

Conflict of interest The authors declare that they have no conflict of interest.

Statement of human and animal rights The study received approval by the medical ethics committee of the VU University medical center.

Informed consent Signed informed consent was obtained from all study participants. 
Open Access This article is distributed under the terms of the Creative Commons Attribution 4.0 International License (http://crea tivecommons.org/licenses/by/4.0/), which permits unrestricted use, distribution, and reproduction in any medium, provided you give appropriate credit to the original author(s) and the source, provide a link to the Creative Commons license, and indicate if changes were made.

\section{References}

1. Clegg A, Young J, Iliffe S et al (2013) Frailty in elderly people. Lancet 381:752-762

2. Cesari M, Marzetti E, Thiem U et al (2016) The geriatric management of frailty as paradigm of "The end of the disease era". Eur J Intern Med 31:11-14

3. Dent E, Kowal P, Hoogendijk EO (2016) Frailty measurement in research and clinical practice: a review. Eur J Intern Med 31:3-10

4. Mitnitski AB, Mogilner AJ, Rockwood K (2001) Accumulation of deficits as a proxy measure of aging. Sci World J 1:323-336

5. Kulminski A, Yashin A, Arbeev K et al (2007) Cumulative index of health disorders as an indicator of aging-associated processes in the elderly: results from analyses of the National Long Term Care Survey. Mech Ageing Dev 128:250-258

6. Romero-Ortuno R, Kenny RA (2012) The frailty index in Europeans: association with age and mortality. Age Ageing 41:684-689

7. Mitnitski A, Howlett SE, Rockwood K (2016) Heterogeneity of human aging and its assessment. J Gerontol A Biol Sci Med Sci. doi:10.1093/gerona/glw089

8. Searle SD, Mitnitski A, Gahbauer EA et al (2008) A standard procedure for creating a frailty index. BMC Geriatr 8:24

9. Saum KU, Dieffenbach AK, Muller H et al (2014) Frailty prevalence and 10-year survival in community-dwelling older adults: results from the ESTHER cohort study. Eur J Epidemiol 29:171-179

10. Mitnitski A, Song X, Rockwood K (2012) Trajectories of changes over 12 years in the health status of Canadians from late middle age. Exp Gerontol 47:893-899

11. Armstrong JJ, Godin J, Launer LJ et al (2016) Changes in frailty predict changes in cognition in older men: the Honolulu-Asia aging study. J Alzheimers Dis 53:1003-1013

12. Huisman M, Poppelaars J, van der Horst M et al (2011) Cohort profile: the Longitudinal Aging Study Amsterdam. Int J Epidemiol 40:868-876

13. Hoogendijk EO, Deeg DJH, Poppelaars J et al (2016) The Longitudinal Aging Study Amsterdam: cohort update 2016 and major findings. Eur J Epidemiol 31:927-945

14. Kriegsman DM, Penninx BW, van Eijk JT et al (1996) Selfreports and general practitioner information on the presence of chronic diseases in community dwelling elderly. A study on the accuracy of patients' self-reports and on determinants of inaccuracy. J Clin Epidemiol 49:1407-1417

15. van Sonsbeek JLA (1988) Methodological and substantial aspects of the OECD indicator of chronic functional limitations. Maandber Gezondh (CBS) 88:4-17

16. Galenkamp H, Braam AW, Huisman M et al (2011) Somatic multimorbidity and self-rated health in the older population. J Gerontol B Psychol Sci Soc Sci 66:380-386
17. Radloff L (1977) The CES-D Scale: a self-report depression scale for research in the general population. Appl Psychol Meas $1: 385-401$

18. Stel VS, Smit JH, Pluijm SM et al (2004) Comparison of the LASA physical activity questionnaire with a 7-day diary and pedometer. J Clin Epidemiol 57:252-258

19. Comijs HC, Deeg DJ, Dik MG et al (2002) Memory complaints; the association with psycho-affective and health problems and the role of personality characteristics. A 6-year follow-up study. J Affect Disord 72:157-165

20. Folstein MF, Folstein SE, McHugh PR (1975) "Mini-mental state". A practical method for grading the cognitive state of patients for the clinician. J Psychiatr Res 12:189-198

21. Sanders JB, Bremmer MA, Deeg DJ et al (2012) Do depressive symptoms and gait speed impairment predict each other's incidence? A 16-year prospective study in the community. J Am Geriatr Soc 60:1673-1680

22. Theou O, Brothers TD, Mitnitski A et al (2013) Operationalization of frailty using eight commonly used scales and comparison of their ability to predict all-cause mortality. J Am Geriatr Soc 61:1537-1551

23. Rockwood K, Andrew M, Mitnitski A (2007) A comparison of two approaches to measuring frailty in elderly people. J Gerontol A Biol Sci Med Sci 62:738-743

24. Rockwood K, Mitnitski A (2006) Limits to deficit accumulation in elderly people. Mech Ageing Dev 127:494-496

25. Rockwood K, Mitnitski A (2007) Frailty in relation to the accumulation of deficits. J Gerontol A Biol Sci Med Sci 62:722-727

26. Wallace LM, Theou O, Pena F et al (2015) Social vulnerability as a predictor of mortality and disability: cross-country differences in the survey of health, aging, and retirement in Europe (SHARE). Aging Clin Exp Res 27:365-372

27. Hoogendijk EO, van Hout HP, Heymans MW et al (2014) Explaining the association between educational level and frailty in older adults: results from a 13-year longitudinal study in the Netherlands. Ann Epidemiol 24:538-544

28. Hoogendijk EO, van Hout HP, van der Horst HE et al (2014) Do psychosocial resources modify the effects of frailty on functional decline and mortality? J Psychosom Res 77:547-551

29. Hoogendijk EO, Suanet B, Dent E et al (2016) Adverse effects of frailty on social functioning in older adults: results from the Longitudinal Aging Study Amsterdam. Maturitas 83:45-50

30. Fried LP, Tangen CM, Walston J et al (2001) Frailty in older adults: evidence for a phenotype. J Gerontol A Biol Sci Med Sci 56:M146-M156

31. Cesari M, Gambassi G, van Kan GA et al (2014) The frailty phenotype and the frailty index: different instruments for different purposes. Age Ageing 43:10-12

32. Clegg A, Bates C, Young J et al (2016) Development and validation of an electronic frailty index using routine primary care electronic health record data. Age Ageing 45:353-360

33. Hoogendijk EO, van Kan GA, Guyonnet S et al (2015) Operationalization of a frailty index using routine data from the Toulouse Frailty Clinic. Geriatr Gerontol Int 15:519-520

34. Drubbel I, de Wit NJ, Bleijenberg N et al (2013) Prediction of adverse health outcomes in older people using a frailty index based on routine primary care data. J Gerontol A Biol Sci Med Sci 68:301-308 